\title{
Declining Fruit and Vegetable Nutrient Composition: What Is the Evidence?
}

\author{
Donald R. Davis ${ }^{1,2,3}$ \\ Biochemical Institute, The University of Texas, Austin, TX 78712; and Bio-Communications \\ Research Institute, 3100 North Hillside Avenue, Wichita, KS 67219
}

Additional index words. nutritive value, history, dilution effect, genetic dilution effect, agriculture, grains

\begin{abstract}
Three kinds of evidence point toward declines of some nutrients in fruits and vegetables available in the United States and the United Kingdom: 1) early studies of fertilization found inverse relationships between crop yield and mineral concentrations - the widely cited "dilution effect"; 2) three recent studies of historical food composition data found apparent median declines of $5 \%$ to $\mathbf{4 0 \%}$ or more in some minerals in groups of vegetables and perhaps fruits; one study also evaluated vitamins and protein with similar results; and 3) recent side-by-side plantings of low- and high-yield cultivars of broccoli and grains found consistently negative correlations between yield and concentrations of minerals and protein, a newly recognized genetic dilution effect. Studies of historical food composition data are inherently limited, but the other methods can focus on single crops of any kind, can include any nutrient of interest, and can be carefully controlled. They can also test proposed methods to minimize or overcome the diluting effects of yield whether by environmental means or by plant breeding.
\end{abstract}

This article summarizes three kinds of evidence pointing toward declines during the last 50 to 100 years in the concentration of some nutrients in vegetables and perhaps also in fruits available in the United States and the United Kingdom.

\section{INVERSE RELATIONS BETWEEN PLANT YIELD AND MINERAL CONCENTRATION}

This article summarizes three kinds of evidence pointing toward declines during the last 50 to 100 years in the concentration of some nutrients in vegetables and perhaps also in fruits available in the United States and the United Kingdom. It has been noted since the 1940s that yield increases produced by fertilization, irrigation, and other environmental means tend to decrease the concentrations of minerals in plants. Jarrell and Beverly (1981) reviewed the evidence for this well-known "dilution effect." Although their review has been cited over 180 times (60 times from 2000 on), few mentions of the dilution effect contain a reference, suggesting that the effect is widely regarded as common knowledge. Citations to the review are diverse, involving (in descending order), grains, fruits and vegetables, trees and shrubs, legumes, pasture plants, and flowers. The most commonly cited fruits and vegetables are tomatoes, potatoes, taro, onions, peppers, and berries.

Jarrell and Beverly cited the example of red raspberry plants grown in soil with 12 ppm of phosphorus (P) and fertilized with additional amounts of 0,22 , and 44 ppm $P$ (Hughes et al., 1979). After 8 months, plants grown with $44 \mathrm{ppm}$ of added $\mathrm{P}$ had $\approx 20 \%$

Received for publication 24 Mar. 2008. Accepted for publication 12 Oct. 2008.

${ }^{1}$ Retired from the University of Texas.

${ }^{2}$ Based on a colloquium presentation to the annual conference of the American Society for Horticultural Science, 18 July 2007.

${ }^{3}$ To whom reprint requests should be addressed; e-maild.r.davis@mail.utexas.edu higher concentration of $\mathrm{P}$ than unfertilized plants (dry weight basis). However, the concentrations of all eight other measured minerals declined, usually by $20 \%$ to $55 \%$ (Fig. 1 ). Fertilization produced large increases in plant dry matter, $37 \%$ at 22 ppm and $119 \%$ at $44 \mathrm{ppm}$. Thus, the fertilized plants contained larger absolute amounts of minerals than the unfertilized plants, but these amounts were sufficiently diluted by the increased dry matter that all mineral concentrations declined, except for P.

\section{APPARENT NUTRIENT DECLINES IN HISTORICAL FOOD COMPOSITION DATA}

There are three quantitative reports of apparent median or average declines of nutrients in groups of vegetables or fruits (Davis et al., 2004; Mayer, 1997; White and Broadley, 2005). The groups of foods usually numbered from 20 to 45 . All authors calculated ratios of nutrient contents, $\mathrm{R}=$ new/old, for each food and nutrient, where the new and old dates differed by $\approx 50$ to 70 years. To assess possible declines in the groups as a whole, Mayer and White and Broadley calculated geometric means of $\mathrm{R}$ for each nutrient and used $t$ tests of the hypotheses that the group geometric means equaled 1 . (Geometric means derive from means of $\log$ $\mathrm{R}$ values.) Davis et al. (2004) and Davis (2006) noted that the distributions of $\log R$ usually deviate significantly or strongly from the normality assumption of $t$ tests and associated confidence intervals (CIs). They preferred the alternate statistical method of testing the hypotheses that the group medians of $\mathrm{R}$ equaled 1. For this purpose, they used sign (quantile) tests and CIs that make no assumption about the distributions of R. They also compared results of the two statistical methods. Mayer calculated $\mathrm{R}$ values based on nutrient concentrations per fresh weight, whereas the others calculated $\mathrm{R}$ values on an equal moisture/dry weight basis. Nutrient content data came from U.K. foods (Mayer and White and Broadley) and U.S. foods (Davis et al. and White and Broadley). In some cases, White and Broadley evidently used the same U.K. data as Mayer; $\approx 40 \%$ of White and Broadley's R values for U.K. vegetables and fruits are the same as Mayer's ( $\pm 5 \%$ after adjustment to dry weight basis).

Figures 2 through 6 show the major results, after recalculation by me to a consistent, conservative analysis: median $\mathrm{R}$ values on a dry weight basis with distributionindependent $95 \%$ CIs and statistical significance by two-tailed sign tests (Davis, 2006; Davis et al., 2004). For comparison, the figures also show geometric mean $\mathrm{R}$ values and two-tailed statistical significance as originally reported, on a fresh weight basis in the case of Mayer's data (Fig. 2).

These Figures 2 through 6 point strongly toward apparent median nutrient declines (median $\mathrm{R}<1$ ). Excluding Mayer's results, which partially duplicate White and Broadley's U.K. findings, and excluding the energy source, carbohydrate (Fig. 3), there are 33 nutrient comparisons in Figures 3 through 6 . Among the 33 median $R$ values, 25 (76\%) are less than 1 (declines), and 11 (33\%) are sufficiently so to be statistically significant $(P<$ $0.05)$. In contrast, among the eight medians that slightly exceed 1 , none are statistically significant. The strongest evidence for declines occurs for minerals in vegetables, especially calcium and copper $(\mathrm{Cu})$, with median declines $\approx 17 \%$ and $80 \%$. This $80 \%$ decline for $\mathrm{Cu}$ is perhaps questionably large, but $\mathrm{Cu}$ also showed the largest dilution effect among the eight minerals reported in red raspberry plants (Fig. 1). For fruits, my recalculated median $\mathrm{R}$ values show only relatively small and uncertain declines in minerals (Figs. 2 and 5).

The one study that considered protein and vitamins found apparent median declines in 43 garden crops (nearly all vegetables) amounting to $6 \%$ for protein and $15 \%$ to $38 \%$ for three of the five vitamins studied (Fig. 3).

For P, U.S. data point toward declines with median $\mathrm{R}=0.91$ in Figure $3(P=0.002)$ 


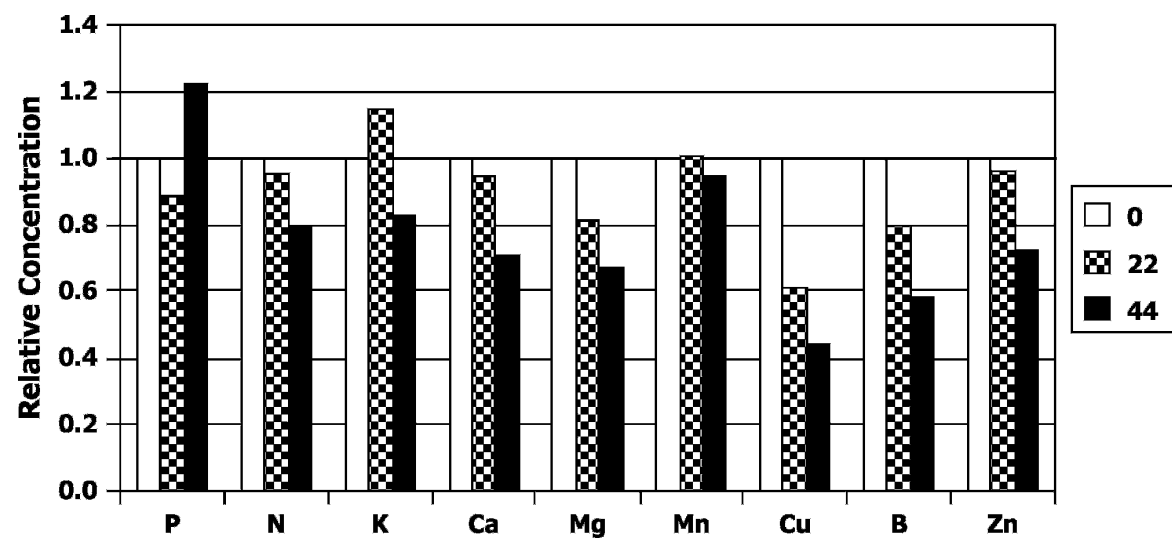

Fig. 1. Dilution effects of phosphorus fertilization in red raspberry plants; 0,22 , and 44 ppm added to soil containing 12 ppm (Hughes et al., 1979; dry weight basis). The relative plant dry weight was, respectively, 1:1.4:2.2.

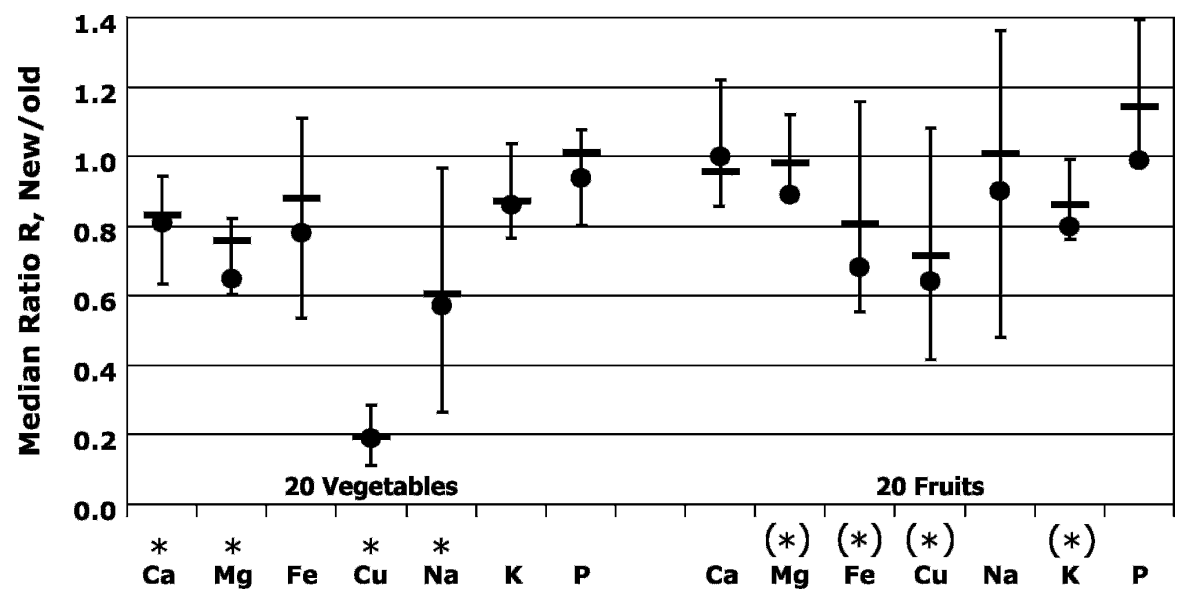

Fig. 2. Apparent changes in nutrient concentrations in 20 vegetables and 20 fruits with $95 \%$ confidence intervals (partially recalculated from Mayer, 1997; U.K. data, 1930s to 1980s). $\bullet$ Originally published geometric mean R values, fresh weight basis. *Originally published geometric mean $\mathrm{R}<1$ by $t$ test, $P$ $\leq 0.014$ (fresh weight basis) confirmed except for sodium by median $\mathrm{R}<1$ by sign test (dry weight basis), $P=0.041$ for calcium, 0.0026 for magnesium, 0.0000 for copper, 0.096 for sodium. $(*)$ Originally published geometric mean $\mathrm{R}<1$ by $t$ test, $P \leq 0.016$ (fresh weight basis), not confirmed by median $\mathrm{R}<1$ by sign test (dry weight basis), $P>0.05$, mainly because of adjustment for increased water in the recent fruits (median $7 \%$ difference).

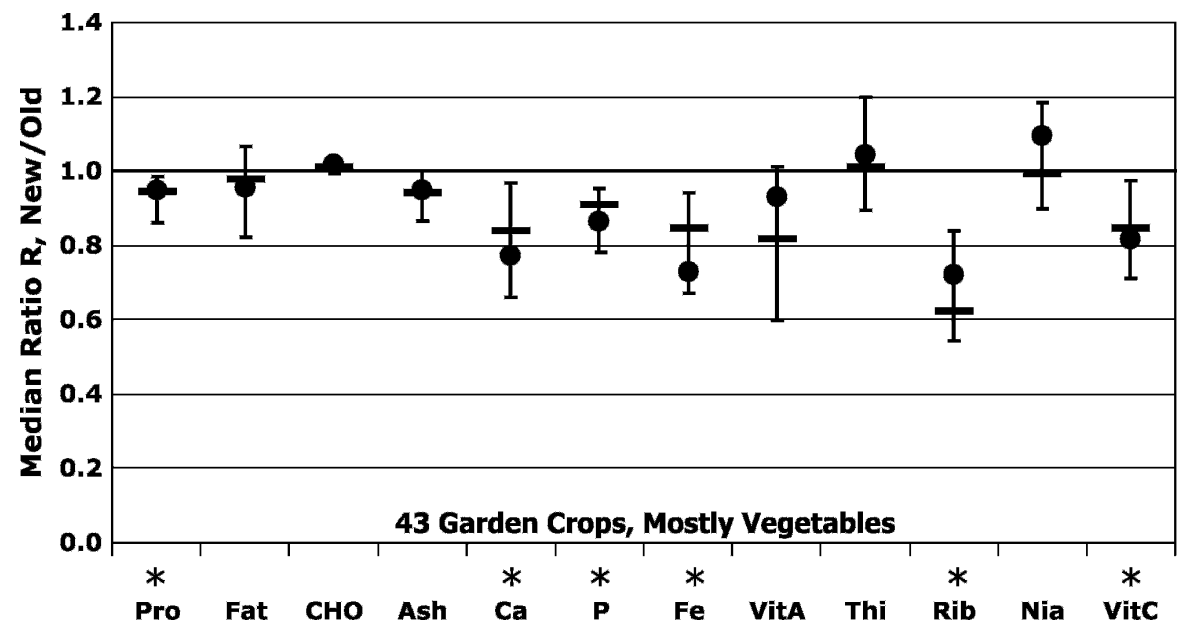

Fig. 3. Apparent changes in nutrient concentrations in 43 garden crops (mostly vegetables) with $95 \%$ confidence intervals, dry weight basis (Davis et al., 2004; USDA data published in 1950 and 1999). Geometric mean $\mathrm{R}$ values for comparison. *Median $\mathrm{R}<1$ by sign test, $P=0.014$ to 0.002 , and geometric mean $\mathrm{R}<1$ by $t$ test, $P \leq 0.010$, except for protein $P=0.14$. and Fig. $6(P=0.17)$. However, median $\mathrm{R}$ values are slightly (but not reliably) greater than 1 in U.K. data (Figs. 2, 4, and 5).

The statistical analyses cited here account for all random uncertainties in the historical data (e.g., sampling, analytical and environmental variations). However, with historical data, one can never exclude possible systematic errors that could affect any of the median $\mathrm{R}$ values in either direction. For example, it is known that some early measurements of iron $(\mathrm{Fe})$ in foods were too high, because they failed to sufficiently remove clinging soil, which may have $10^{4}$-fold higher levels of $\mathrm{Fe}$ than do foods. Too-high early values cause the spurious appearance of declines, and this systematic error might explain the extraordinarily low median $\mathrm{R} \approx 0.3$ for $\mathrm{Fe}$ in Figure 6 (unlike $\mathrm{R} \approx 0.8$ to 1.0 in Figs. $2-5$ ). One can always postulate other systematic errors to question any individual median $\mathrm{R}$ value from historical data. That is why I call these $\mathrm{R}$ values "apparent." However, it would seem scarcely credible to attribute all the statistically significant median $\mathrm{R}<1$ to multiple systematic errors, each one operating in only one direction. Moreover, the results of historical studies are consistent with the two other kinds of evidence discussed here.

Even when group median $\mathrm{R}$ values are reliably $<1$, many individual foods and nutrients show $\mathrm{R}>1$ as shown by box plots for 12 nutrients in Davis et al. (2004, their Fig. 1). For example, their median $\mathrm{R}$ is 0.62 for riboflavin $(P=0.008)$ (Fig. 3 here), but 12 of 42 individual $\mathrm{R}$ values $(29 \%)$ exceed 1 . Some $\mathrm{R}>1$ presumably reflect random errors in the numerators and denominators of $\mathrm{R}$. However, the authors' analysis of their most reliable 256 individual $\mathrm{R}$ values still found that roughly $11 \%$ to $16 \%$ exceed 1 (their Table 4). They suggested that these $\mathrm{R}>1$ likely reflect mostly genetic variations in the cultivars used. Furthermore, they argued that these $\mathrm{R}>1$ cast doubt on the generality of several potential environmental explanations of the median declines such as soil mineral depletion or changes in agricultural practices. Another evidence against the generality of the soil-mineral depletion hypotheses is their finding that median $\mathrm{R}$ values are less than 1 for protein, $\mathrm{P}$, and ash [mostly potassium $(\mathrm{K})$ ] (Fig. 3) despite presumably increased use of $\mathrm{N}-\mathrm{P}-\mathrm{K}$ fertilizers in the modern era compared with the 1940s and earlier.

In addition to the three quantitative reports for U.S. and U.K. foods discussed here, Ekholm et al. (2007) reported declines in mostly Finnish foods from the mid-1970s to the 2000s. Considering 17 vegetables, six berries, four grains, and apples as a group, they reported statistically significant "average" declines in the nutrients $\mathrm{K}$, manganese, zinc, and $\mathrm{Cu}$ but an increase in selenium $(\mathrm{Se})$ (attributed to Se fertilization begun in Finland in 1985). Also, there were downward trends in magnesium $(\mathrm{Mg})$, calcium $(\mathrm{Ca}), \mathrm{P}$, and $\mathrm{Fe}$ with no upward trends in nutrient elements. Curiously, the authors did not report the size of these changes (and did not respond to requests for additional information). 


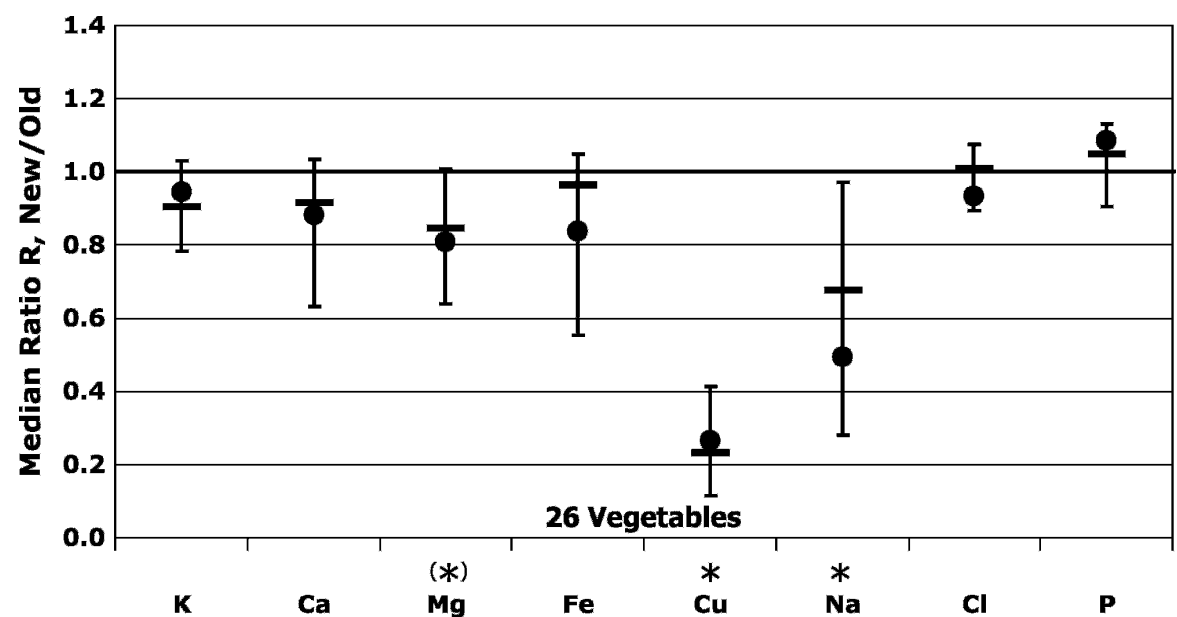

Fig. 4. Apparent changes in nutrient concentrations in 26 vegetables with $95 \%$ confidence intervals, dry weight basis (White and Broadley, 2005; U.K. data, 1930s to 1980s). Originally published geometric mean $\mathrm{R}$ values. *Originally published geometric mean $\mathrm{R}<1$ by $t$ test, $P=0.0000$ (copper) and 0.004 (sodium), confirmed by median $\mathrm{R}<1$ by sign test, $P=0.0001$ for copper, 0.004 for sodium. $\left.{ }^{*}\right)$ Originally published geometric mean $\mathrm{R}<1$ by $t$ test, $P=0.023$, not confirmed by median $\mathrm{R}<1$ by sign test $(P=0.17)$.

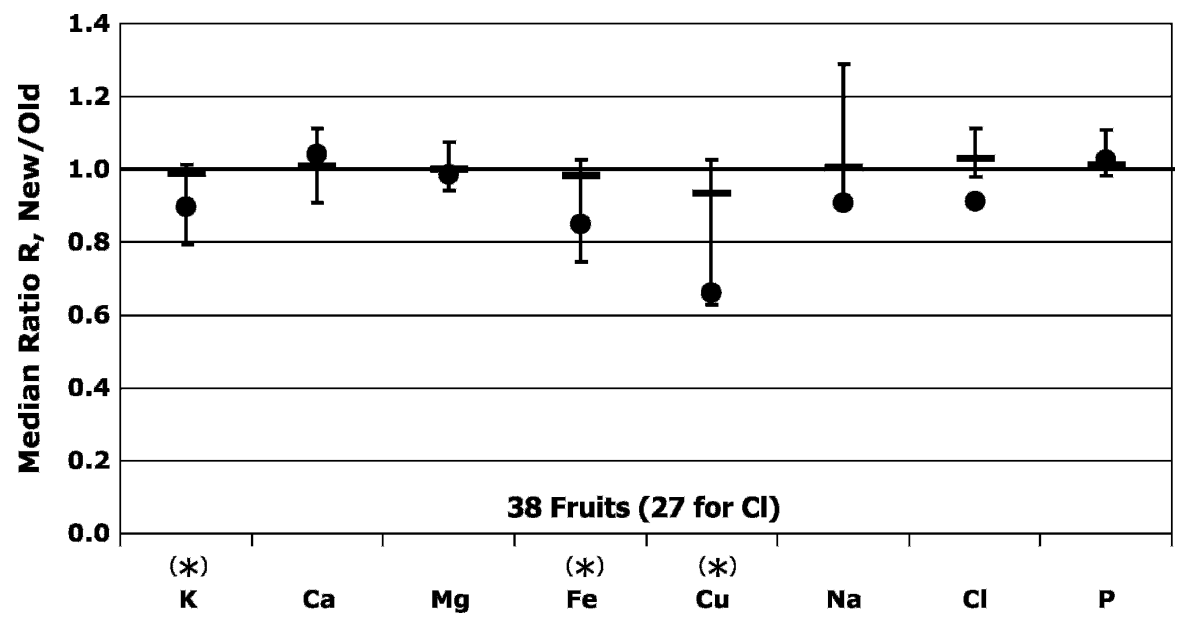

Fig. 5. Apparent changes in nutrient concentrations in 38 fruits $(27$ for $\mathrm{Cl}$ ) with $95 \%$ confidence intervals dry weight basis (White and Broadley, 2005; U.K. data, 1930s to 1980s). Originally published geometric mean $\mathrm{R}$ values. (*) Originally published geometric mean $\mathrm{R}<1$ by $t$ test, $P=0.037-0.007$, not confirmed by median $\mathrm{R}<1$ by sign test $(P=0.26$ for potassium, 0.42 for iron, and 0.24 for copper $)$ (Davis, 2006)

\section{SIDE-BY-SIDE COMPARISONS OF} HIGH- AND LOW-YIELD CULTIVARS

There are four studies known to me in which historical or other collections of cultivars of a single food were grown side by side for purposes of comparing their nutrient content. The foods are broccoli, wheat (two studies), and maize. Side-by-side comparisons are very powerful, because they eliminate all the potential confounding in comparisons of historical data (previous section). They also eliminate the need with historical data to average over large numbers of foods. All environmental conditions are constant, including soil, fertilization, irrigation, pest control, climate, harvest, sampling, and analytical methods. The only variation is the genetics of the cultivars.

The first such study measured $\mathrm{Ca}$ and $\mathrm{Mg}$ concentrations in 27 commercial broccoli hybrids, released mostly in the 1980 s and 1990s, grown in 1996 and 1997 in South Carolina (Farnham et al., 2000). The authors reported correlation coefficients between mineral concentration and head weight (dry weight basis). These correlations were all negative and statistically significant for both years, -0.46 and -0.63 for $\mathrm{Ca}$ and -0.69 and -0.68 for $\mathrm{Mg}(P<0.01$ except $P<0.05$ for the -0.46$)$. Mineral concentrations ranged roughly twofold overall and $\approx 1.3$ - to 1.7 fold among the cultivars with consistently low or high concentrations. The authors did not report yields, but in this experiment, head weight presumably correlates closely with yield (head weight $\times$ harvestable heads/acre), because all cultivars had the same number of plants/acre. Thus, these negative correlation coefficients imply significant inverse relationships between yield and concentrations of $\mathrm{Ca}$ and $\mathrm{Mg}$ in the tested broccoli cultivars.
Broccoli yields have increased rapidly in the United States according to data on production and harvested acreage from the U.S. Department of Agriculture (USDA) - over 4\% per year from 1970 through 2007 (U.S. Department of Agriculture, 2008a and earlier).

Farnham et al. (2000) noted "there may be a barrier to combining high head $\mathrm{Ca}$ or $\mathrm{Mg}$ concentration and [high] head density in a single hybrid." (Head density was nearly proportional to head weight and thus yield.) They also noted that the broccoli Ca concentration in USDA's 1998 Nutrient Database for Standard Reference "is probably high relative to much of the broccoli that would be available to consumers." The authors' mean $\mathrm{Ca}$ concentration for 27 commercial hybrids was $3.4 \pm 0.1 \mathrm{sE} \mathrm{mg} \cdot \mathrm{g}^{-1}$ dry weight in 1996 and 1997, substantially lower than the USDA's reference values published in 1950 (12.9 $\left.\mathrm{mg} \cdot \mathrm{g}^{-1}\right), 1963 \quad\left(9.4 \mathrm{mg} \cdot \mathrm{g}^{-1}\right), 1982$ through $2002\left(5.2 \mathrm{mg} \cdot \mathrm{g}^{-1}\right)$, and since 2003 (4.4 $\left.\mathrm{mg} \cdot \mathrm{g}^{-1}\right)$.

Farnham et al. (2000) suggested a "large impact" from "a dilution effect" in which "hybrids with denser heads accumulate relatively more dry matter (primarily phloem delivered) without increasing $\mathrm{Ca}$ and $\mathrm{Mg}$ (primarily xylem-delivered) in the same relative proportion." Presumably, other broccoli nutrients delivered primarily by xylem would be similarly diluted. However, nutrients not xylem-delivered, and not synthetically limited by xylem-delivered substances, could be independent of head weight, as was found for glucosinolates in broccoli (Farnham et al., 2004).

$\mathrm{Ca}$ and $\mathrm{Mg}$ in broccoli are the first examples known to me of a newly recognized kind of dilution effect, a genetic dilution effect, a term introduced by Davis (2005) after personal communication with Wesley M. Jarrell. Unlike previously known environmental dilution effects caused by fertilization and other environmental factors (Jarrell and Beverly, 1981), genetic dilution effects manifest under fixed environmental conditions. The variations in broccoli $\mathrm{Ca}$ and $\mathrm{Mg}$ concentrations within one crop year (one environment) are attributable solely to genetic differences.

However, interactions must be expected between genetics and the environment. Farnham et al. (2000) found "unexpectedly" large variations between the two crop years, showing that "environment plays an important role in expression of mineral concentration in broccoli hybrid heads." Thus, it may prove possible to ameliorate genetic dilution effects by environmental means. In practice, both genetic and environmental dilution effects seem likely to occur simultaneously and additively and to be potentially ameliorated by environmental means.

Wheat is the second reported food in which cultivars of varying yield were grown side by side and measured for their nutrient contents (Garvin et al., 2002, 2006; Monasterio and Graham, 2000). Garvin et al. measured six minerals in 14 hard red winter wheats grown in two areas of Kansas. The 


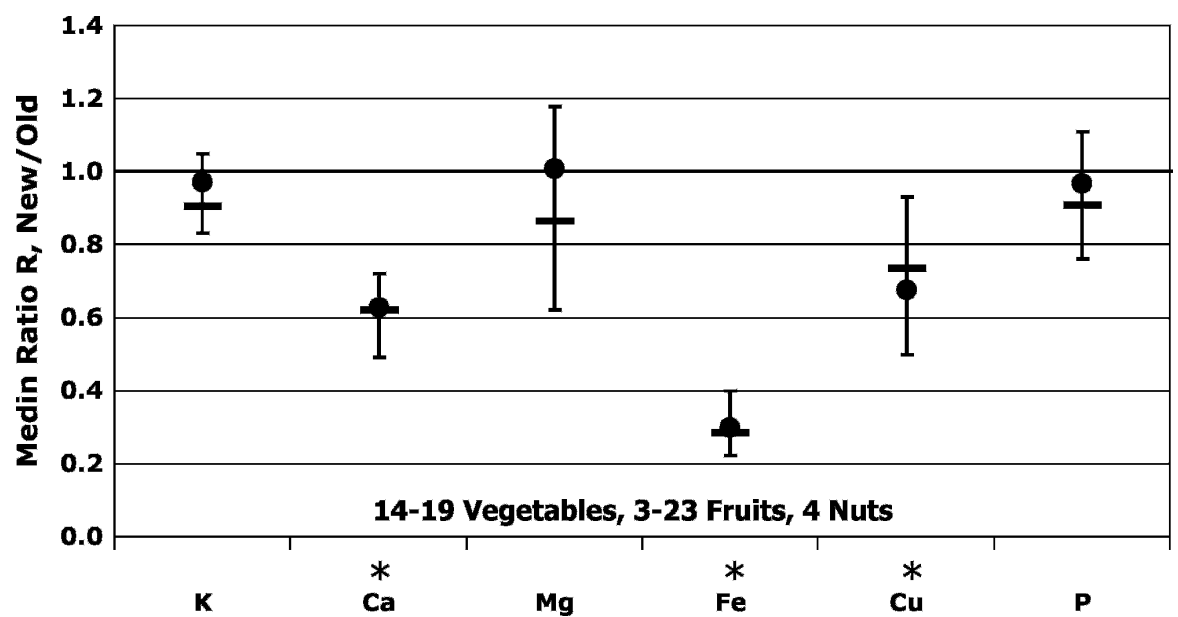

Fig. 6. Apparent changes in nutrient concentrations in 16 to 50 vegetables, fruits, and nuts with $95 \%$ confidence intervals, dry weight basis (White and Broadley, 2005; U.S. data, 1930s to 2004). Originally published geometric mean $\mathrm{R}$ values. *Originally published geometric mean $\mathrm{R}<1$ by $t$ test, $P=0.0009-0.0000$, confirmed by median $\mathrm{R}<1$ by sign test $(P=0.0007$ for calcium, 0.0000 for iron, and 0.019 for copper).

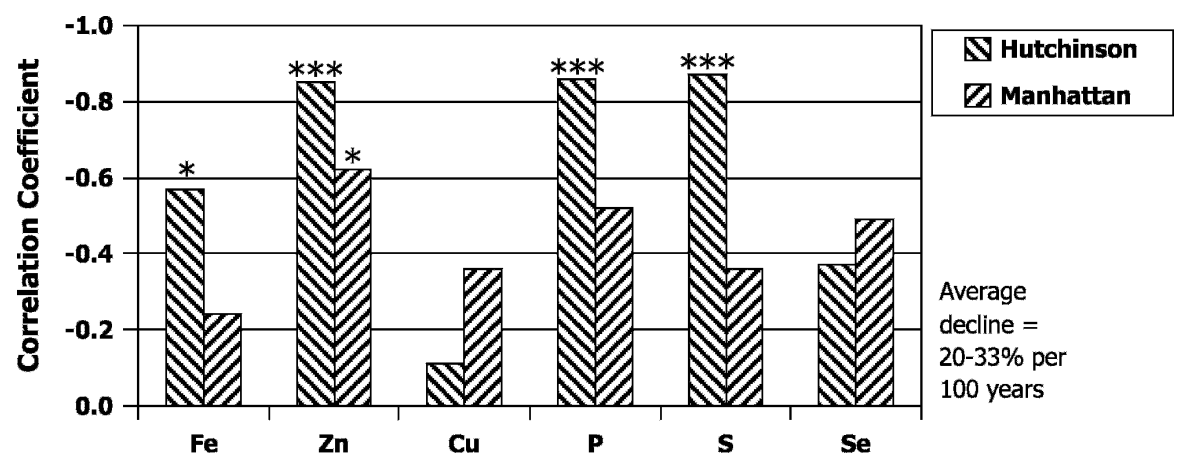

Fig. 7. Inverse correlations between yield and mineral concentration in 14 hard red winter wheats grown side by side in two locations in Kansas. The wheat varieties were previously grown in the Great Plains between 1873 and 1995 (Garvin et al., 2002, 2006). Correlations differ from zero with statistical significance, $* P<0.05, * * * P<0.001$.

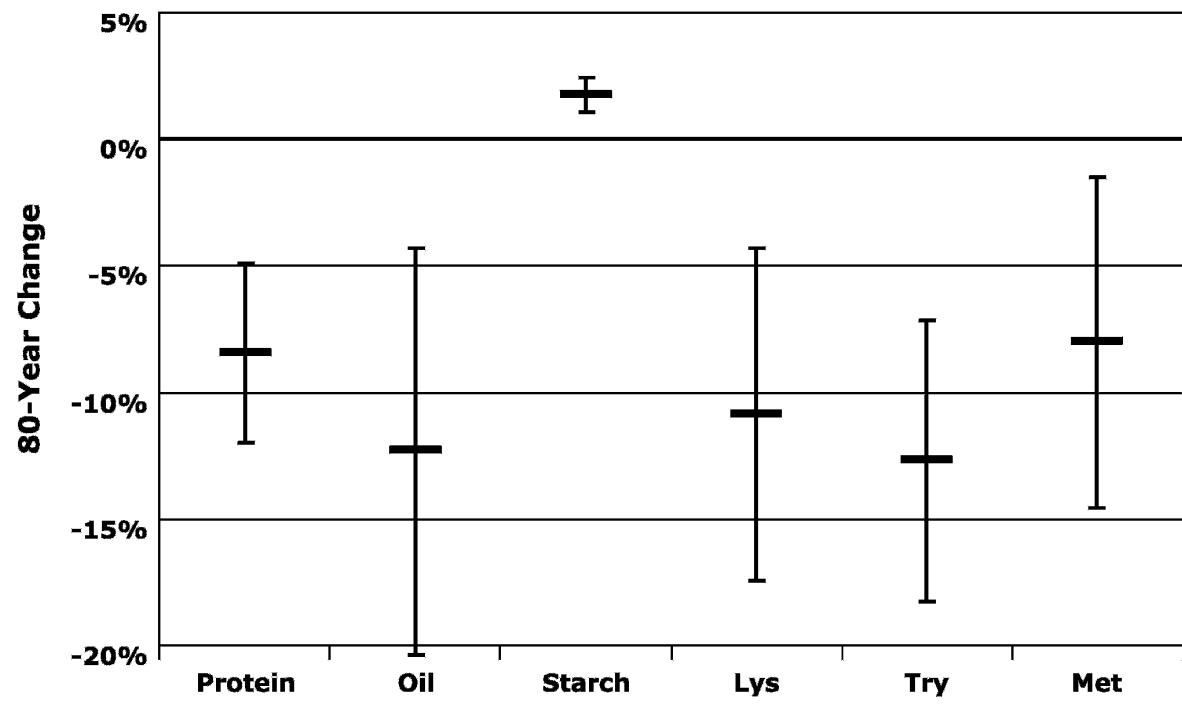

Fig. 8. Eighty-year changes in nutrient concentrations found in a study of 45 maize cultivars grown side by side in Iowa and California (means $\pm 95 \%$ confidence intervals). These cultivars were grown previously in the United States between 1920 and 2001 (Scott et al., 2006). Means are calculated from slopes and intercepts of reported regression equations (averaged over environment and plant density) with $95 \%$ confidence intervals estimated as $\pm 1.96 \times$ SE. Means differ from zero with statistical significance $P<0.02$ (methionine), $<0.005$ (oil, lysine), and $<0.001$ (protein, starch, tryptophan). cultivars were widely grown in the Great Planes between 1873 and 1995 and varied approximately twofold in yield. Similar to the study of broccoli, all of the reported correlation coefficients between mineral concentrations and yield are negative, but only five of the 12 correlations are sufficiently large to be statistically significant (Fig. 7). The reported average rate of decline of the six minerals is $0.20 \%$ to $0.33 \%$ per year, equivalent to 100 -year declines of $22 \%$ to $39 \%$, respectively.

As a small part of a paper on wheat breeding, Monasterio and Graham (2000) briefly mention studying an historical set of bread wheat cultivars introduced in Mexico between 1950 and 1992. They conducted five experiments over 3 years in Mexico, apparently with 16 cultivars. Graphs of mineral concentration versus year of introduction showed statistically significant declines in $\mathrm{Fe}$, zinc, and $\mathrm{P}-$ on average, $\approx 0.3 \%$ per year (similar to Garvin et al.). Yields increased $\approx 1 \%$ per year.

A detailed study in maize included 45 cultivars grown side by side in Iowa and California (Scott et al., 2006). These cultivars were widely grown in the midwestern United States between 1920 and 2001 and varied a little over twofold in yield. The authors reported nutrient concentrations as a function of year of introduction in the form of regression equations. From the equations I calculated 80-year declines in concentrations of protein, oil, and three amino acids $(8 \%$ to $13 \%$ ) and the corresponding increase in starch (2\%) (Fig. 8). All changes are statistically significant $(P<0.02$ to $<0.001)$. [In wheat and barley, protein concentrations have declined much more markedly over similar time periods, $30 \%$ to $50 \%$ (Simmonds, 1995).]

Although these four side-by-side studies are limited in number and scope, they show uniformly inverse associations between yield and nutrient concentrations for every nutrient studied so far (other than carbohydrate) - two minerals in broccoli; six minerals in wheat, plus protein, oil; and three amino acids in maize. These four studies suggest to me that genetic dilution effects may be common when selective breeding successfully increases crop yields.

\section{DISCUSSION}

The evidence for nutrient declines began to accumulate in the 1940s with observations of (environmental) dilution effects on minerals in many foods and diverse other plants. Recent studies of historical nutrient content data for fruits and vegetables spanning 50 to 70 years show apparent median declines of $5 \%$ to $40 \%$ or more in minerals, vitamins, and protein in groups of foods, especially in vegetables. Although these apparent declines in individual nutrients may be confounded by systematic errors in historical data, the broad evidence is consistent with more definitive studies and seems difficult to dismiss. The 
unique advantage of historical studies is that they provide our best estimates of real-world changes over long periods, albeit averaged over many foods. [In some fortunate cases, archived food samples permit definitive historical studies of single foods, e.g., 160 years of archived wheat samples from a single farm (Fan et al., 2008).]

Recently, limited numbers of side-by-side comparisons of low- and high-yield cultivars of the same food have proven the existence of genetic dilution effects in which yield increases derive from selective breeding rather than environmental measures such as fertilization. So far, these studies uniformly show small to moderate tradeoffs between yield and nutrient concentrations, suggesting a broad phenomenon.

The "green revolution" of the 1960s and 1970 s increased the yields of grains by twoto threefold or sometimes more in major developing countries. Less well known are the mostly smaller but broad increases in U.S. yields of horticultural crops during that time and continuing to the present. The USDA has published extensive data on U.S. production, harvested area, and yield of many vegetables and some fruits and melons (U.S. Department of Agriculture, 2008a, 2008b and earlier). Plots of these yields since 1960 or 1970 for 24 available vegetables uniformly show increases with time; nearly all well fit by straight lines with a mean slope of $2.0 \% \pm$ $0.9 \%$ SD per year (corresponding to a 30 -year yield increase of 1.8-fold). For six available fruits (apple, orange, banana, grapefruit, peach, and pineapple), the mean slope since 1976 is approximately half as large, $0.9 \% \pm$ $1.2 \%$ SD per year (a 30-year increase of 1.3fold). The difference between these slopes is statistically significant by Mann-Whitney test (two-tailed $P=0.014$ ). Although limited in the case of fruits, the USDA's data thus suggest that yields have increased more in vegetables than in fruits, which may help explain the findings of larger nutrient declines in vegetables. Assuming that selective breeding has contributed to increasing yields in at least vegetables, this explanation seems plausible in view of the relative difficulty of breeding long-lived fruits. Other potential factors are the botanical and cultural differences between fruits and vegetables such as different botanical parts, different contributions of "hybrid vigor," and the use of thinning to increase the size of some fruits.

The relative contributions of cultural practices and plant breeding to horticultural yield increases have not been documented. However, it seems clear that yield is generally a major goal of vegetable breeders: "The intensive varietal improvements of vegetable crops for high yield and improved nutritional quality are primary breeding objectives of various national and international programs" (Singh, 2007). ("Improved nutritional quality" is a recent goal generally focused on single nutrients. At least so far, this goal is not sufficiently realized to prevent the observed historical declines.)

In fruits, vegetables, and grains, usually $80 \%$ to $90 \%$ of the dry weight yield is carbohydrate. Thus, when breeders select for high yield, they are, in effect, selecting mostly for high carbohydrate with no assurance that dozens of other nutrients and thousands of phytochemicals will all increase in proportion to yield. Thus, genetic dilution effects seem unsurprising.

Further studies are needed to assess the generality of dilution effects among foods and to greatly expand the numbers of nutrients and phytochemicals considered. Side-by-side comparisons of multiple cultivars in multiple environments can provide rigorous answers to the many remaining uncertainties. They are also well suited for testing proposed environmental and genetic methods to overcome dilution effects. Specifically, we would like to find ways to decrease the inverse correlation coefficients between yield and nutrient concentration or to decrease the negative slopes in plots of nutrient concentration vs. yield.

Over three billion of the world's population is malnourished in nutrient elements and vitamins (Welch and Graham, 2004), including in developed countries. Vegetables and fruits are among the richest sources of many nutrients. Thus, declining nutrient concentrations in horticultural products are most unwelcome. Past and ongoing efforts to increase yields, combined with apparent broad tradeoffs between yield and the concentrations of perhaps half of all essential nutrients, work against recent efforts to increase one or a few micronutrients in individual foods.

\section{Literature Cited}

Davis, D.R. 2005. Trade-offs in agriculture and nutrition. Food Technol. 59:120.

Davis, D.R. 2006. Commentary on: 'Historical variation in the mineral composition of edible horticultural products'. J. Hort. Sci. Biotechnol. 81:553-554.

Davis, D.R., M.D. Epp, and H.D. Riordan. 2004. Changes in USDA food composition data for 43 garden crops, 1950 to 1999. J. Amer. Coll. Nutr. 23:669-682.

Ekholm, P., H. Reinivuo, P. Mattila, H. Pakkala, J. Koponen, A. Happonen, J. Hellström, and M.-L. Ovaskainen. 2007. Changes in the mineral and trace element contents of cereals, fruits and vegetables in Finland. J. Food Compos. Anal. 20:487-495.

Fan, M.-S., F.-J. Zhao, S.J. Fairweather-Tait, P.R Poulton, S.J. Dunham, and S.P. McGrath. 2008. Evidence of decreasing mineral density in wheat grain over the last 160 years. J. Trace Elem. Med. Biol. (in press).

Farnham, M.W., M.A. Grusak, and M. Wang. 2000. Calcium and magnesium concentration of inbred and hybrid broccoli heads. J. Amer. Soc. Hort. Sci. 125:344-349.

Farnham, M.W., P.E. Wilson, K.K. Stephenson, and J.W. Fahey. 2004. Genetic and environmental effects on glucosinolate content and chemoprotective potency of broccoli. Plant Breed. 123:60-65.

Garvin, D.F., R.M. Welch, and J.W. Finley. 2006. Historical shifts in the seed mineral micronutrient concentration of US hard red winter wheat germplasm. J. Sci. Food Agr. 86:22132220.

Garvin, D.F., R.M. Welch, J.W. Finley, A.K. Fritz, E. Donmez, J.P. Shroyer, and G.M. Paulsen. 2002. Seed micronutrient contents of a historical collection of hard red winter wheats (poster presentation). In: Annual meeting abstracts [CD-ROM]. Amer. Soc. Agron./Crop Sci. Soc. Amer./Soil Sci. Soc. Amer., Madison, WI.

Hughes, M., M.H. Chaplin, and L.W. Martin. 1979. Influence of mycorrhiza on the nutrition of red raspberries. HortScience 14:521-523.

Jarrell, W.M. and R.B. Beverly. 1981. The dilution effect in plant nutrition studies, p. 197 224. In: Brady, N.C. (ed.). Adv. Agron. Vol. 34. Academic Press, New York, NY.

Mayer, A.-M. 1997. Historical changes in the mineral content of fruits and vegetables. Brit. Food J. 99:207-211.

Monasterio, I. and R.D. Graham. 2000. Breeding for trace minerals in wheat. Food Nutr. Bull. 21:392-396.

Scott, M.P., J.W. Edwards, C.P. Bell, J.R. Schussler, and J.S. Smith. 2006. Grain composition and amino acid content in maize cultivars representing 80 years of commercial maize varieties. Maydica 51:417-423.

Simmonds, N.W. 1995. The relation between yield and protein in cereal grain. J. Sci. Food Agr. 67:309-315.

Singh, R.J. 2007. Preface, p. 1-3. In: Singh, R.J. (ed.). Genetic resources, chromosome engineering, and crop improvement, Volume 3 : Vegetable crops. CRC Press, Boca Raton, FL.

U.S. Department of Agriculture. 2008a. Vegetables and melons yearbook. U.S. Dept. Agr., Tables 5 and 6, Washington, DC. 18 Sept. 2008. $<$ http://usda.mannlib.cornell.edu/MannUsda/ viewDocumentInfo.do?documentID $=1212>$.

U.S. Department of Agriculture. 2008b. Economics, statistics, and market information system. Commodities (vegetables and melons, potatoes, fruits and nuts). U.S. Dept. Agr., 18 Sept. 2008. <http://usda.mannlib.cornell.edu/Mann Usda/viewTaxonomy.do?taxonomyID $=2>$.

Welch, R.M. and R.D. Graham. 2004. Breeding for micronutrients in staple food crops from a human nutrition perspective. J. Expt. Bot. 55: 353-364.

White, P.J. and M.R. Broadley. 2005. Historical variation in the mineral composition of edible horticultural products. J. Hort. Sci. Biotechnol. 80:660-667. 